УДК 331.1

DOI: $10.17223 / 19988648 / 36 / 13$

\title{
И.В. Смирнов
}

\section{ПЕРСПЕКТИВЫ ИСПОЛЬЗОВАНИЯ СБАЛАНСИРОВАННОЙ СИСТЕМЫ ДЛЯ ОЦЕНКИ КАДРОВ ПРЕДПРИЯТИЙ}

\begin{abstract}
С середины 90-х г2. в мировой практике менеджмента популярность набрала сбалансированная система показателей, разработанная американскими учёными Дэвидом Нортоном и Робертом Капланом. Система в силу своей простоты и эффективности быстро завоевала популярность даже среди крупнейших корпораций мира. В данной статье освещается кадровая составляющая сбалансированной системы: её состав, особенности и значение, а также возможности её применения для практической работы отделов персонала предприятий для различных отраслей. Особое внимание уделяется рассмотрению сложностей, возникающих при внедрении сбалансированной системы, что вызвано слабой её распространённостью в российской практике. $B$ данной статье эти проблемы анализируются и рассматриваются вопросы их преодоления.

Ключевые слова: сбалансированная система показателей, кадры, оиенка кадров предприятия, системы управления, российские предприятия.
\end{abstract}

Технологический прогресс всего мирового сообщества, и России в частности, привёл к необходимости появления новых систем оценки труда. Постиндустриальное общество, характеризующееся большой долей интеллектуального труда, разносторонностью деятельности рабочего и значительной долей творческих элементов, больше не может опираться на старые системы учёта, разработанные для специфики общества индустриального. Одним из вариантов такой системы стала сбалансированная система показателей (далее - ССП), разработанная Д. Нортоном и Р. Капланом в 90-х гг. ХХ в. В своей системе они нашли место как классической, бухгалтерской системе оценки, так и новым направлениям: работе с клиентами, бизнес-процессам и работе с персоналом. Именно последняя составляющая может стать базой для оценки эффективности труда рабочих в новых экономических условиях. Задачей данной статьи является описание этой составляющей с предложениями категорий по её использованию в качестве базовой при создании новой системы оценки персонала.

Составляющая обучения и развития (также часто называемая составляющей персонала) является слабым местом ССП во время практической реализации. Причиной служит тот факт, что практические принципы современного управления, опираясь на традиционную систему бухгалтерского учёта, открыто утверждают, что снижение расходов на персонал (включая увольнения) - это верная возможность добиться краткосрочного финансового успеха [1. С. 85]. В условиях, когда этот показатель является единственным показателем успеха предприятия, это наиболее простой путь добиться расположения акционеров. В то же время такая политика ведёт к крайне тяжёлым последствиям в долгосрочной перспективе. По данным исследования Ассоциации качества продукции и менеджмента США (QPMA), 70\% руководителей 
компаний, применивших подобную тактику, столкнулись с большим количеством проблем, чем они ожидали. Менее $16 \%$ менеджеров признали сокращения персонала эффективными при 40\% абсолютно неудовлетворённых этой мерой. Ещё одно распространённое заблуждение состоит в том, что сокращение персонала ведёт к росту производительности труда. По данным исследований Census Bureau's Center for Economic Study, из 140000 участвующих в исследовании предприятий в $45 \%$ рост производительности произошёл при росте числа занятых [2. С. 70-73].

С учётом этих данных стоит признать, что персонал и его компетенции являются важной, неотьемлемой частью компании и экономия на них обходится в стратегической перспективе очень дорого. В ССП составляющая обучения и развития занимает особое место, так как находится в основании системы, обеспечивая инфраструктуру остальным трём.

Д. Нортон и Р. Каплан выделяют три основных направления развития кадровой составляющей: возможности работника, возможности информационных систем и мотивацию (делегирование полномочий, соответствие личных целей корпоративным) [1. С. 91].

В направлении возможностей работника в качестве рекомендуемых показателей для оценки выделяются: показатели удовлетворённости работника (они ключевые и, по мнению авторов, должны быть в любой ССП). В данном случае исследователи придерживаются правила «довольный работник - эффективный работник»; показатели сохранения кадровой базы. они отражают стабильность кадрового состава предприятия); эффективность работника, здесь очень распространённым показателем является доход с одного человека.

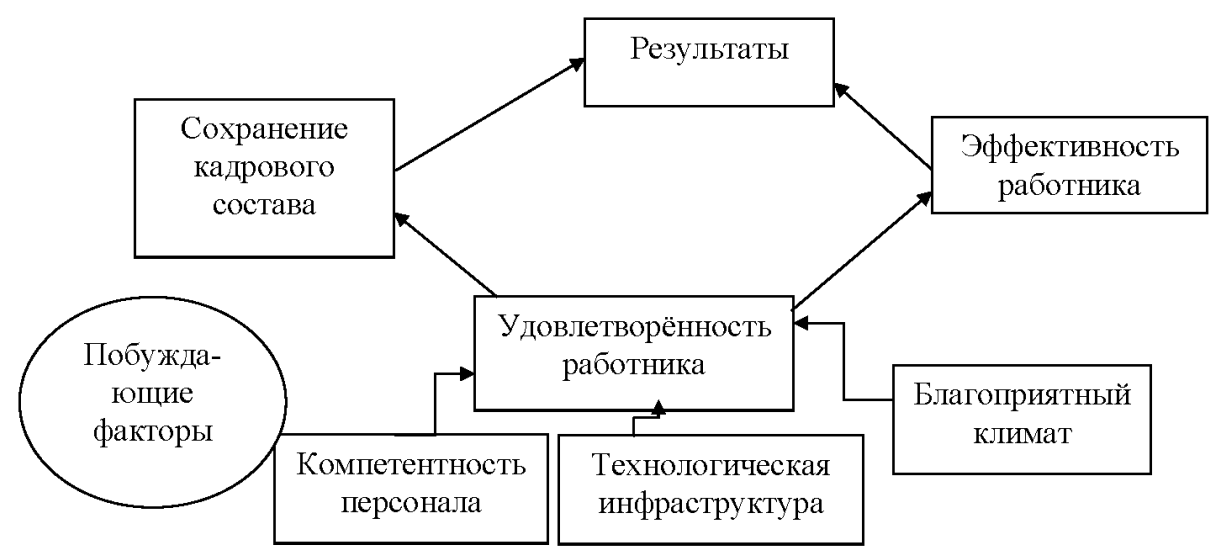

Рис. 1. Составляющая обучения и развития по Д. Нортону и Р. Каплану

Большинство показателей возможностей работника (в частности, наиболее важная - удовлетворённость персонала) измеряются при помощи опросов, тестов и других методов, позволяющих переводить качественную информацию в количественную. 
Наличие такой составляющей расчётов, как возможность информационных систем, объясняется необходимостью иметь нужную информацию для эффективной работы сотрудников. Несмотря на кажущуюся второстепенность, данная проблема достаточно остра, особенно в отечественных компаниях. Эксперт из компании Ernst \& Young Олег Данилин отмечает, что информационные проблемы стали серьёзным препятствием на пути развития многих организаций. Если верхний уровень менеджмента нередко перегружен информацией, то рядовые работники часто чувствуют информационный голод, теряя в эффективности, мотивации и затрачивая время на второстепенную задачу поиска необходимых данных [3]. Отсюда следует, что для компании важно установить контроль за доступностью информации для персонала (что облегчит и обратную связь). Отслеживать эти данные можно при помощи таких показателей, как процент сотрудников, имеющих доступ к данным; процент информатизированных рабочих мест и т.п. [1. С. 96].

Особое внимание уделяется и мотивационной части. Д. Нортон и Р. Каплан утверждают, что лучше всего мотивацию смогут отразить показатели участия сотрудника в повседневных делах организации: число предложений на одного сотрудника [1. С. 96], количество участий в принятии управленческих решений и т.д. Важно отметить, что не нужно игнорировать участие работников в управлении, особенно при внедрении ССП - чем больше они знают о нём и чем больше участвуют в его создании, тем более гладко пройдет процесс внедрения. В нашей стране обычно не принято допускать работников до участия в управлении, хотя это является одним из принципов трудового права и предусмотрено Трудовым кодексом РФ [4. Ст. 52, 53].

М.Г. Браун, в пику другим авторам, предлагает использовать объединяющий индекс кадрового состояния предприятия. Для его измерения требуется проводить ряд мероприятий по сбору необходимой информации [2. С. 104-105]:

- Сегментировать работников по типу обслуживаемых потребителей.

- Минимум раз в год проводить масштабное исследование по выявлению уровня корпоративного духа.

•Ежемесячно уточнять данные по показателям удовлетворённости.

- Сравнивать индивидуальные показатели.

- Выявлять сверхудовлетворённых сотрудников привлечения в важные направления деятельности предприятия.

- Постоянно модернизировать методы сбора информации, вносить необходимое разнообразие. Учитывая уровень доверия к руководству и подобным опросам в нашей стране, следует обратить внимание на использование опосредованных, косвенных методов сбора подобной информации.

Однако даже если применять все приведённые выше методы и требования, результат по составляющей обучения и развития может стать отрицательным при формальном к нему подходе. К сожалению, составляющая работников является наиболее уязвимой, игнорируемой при составлении ССП частью, несмотря на статистические данные, говорящие о её важности. Это категорически недопустимо и требует в случае внедрения на предприятии дополнительного обсуждения с руководством. 
Стоит отметить, что каждое предприятие по-своему уникально и пригодность применения тех или иных показателей возможно установить только после общего анализа его деятельности и определения стратегической направленности. Также важными факторами для определения целей и показателей являются профиль предприятия, структура, отрасль, особенности рынка и многие другие. Соответственно подход к определению критических направлений деятельности в каждом случае индивидуален. К примеру, анализ опыта внедрения ССП, предложенный авторами работ, позволяет выделить отрасли и типы предприятий, которые в наибольшей степени подходят для внедрения, - это крупные промышленные компании, включающие в себя большое количество подразделений. У них достаточно материальных средств для проведения подобных мероприятий, а наличие множества подразделений предоставляет возможность для апробации системы в различных условиях. В то же время небольшие компании вряд ли могут позволить себе сбалансированную систему в её полном формате - возможно, лучше будет использовать её философию, общую концепцию или отдельные элементы (хотя авторами концепции это не рекомендуется).

Однако, несмотря на пропагандируемую эффективность, к ССП возникают некоторые вопросы, что особенно касается российской практики. В современной России количество исследований в этой области крайне велико. Написано большое количество статей, монографий и диссертаций. Однако доля предприятий, где эта система используется, по сравнению с зарубежными странами крайне мала. Возникает естественный вопрос: в чём же причина этого явления?

Из тех материалов, которые предоставляют информацию об ССП, может сложиться представление о ней как о некой панацее для менеджера, возможности при помощи одной универсальной управленческой схемы разрешить разом все проблемы предприятия. Однако это ощущение ложно - ССП всего лишь инструмент, помогающий выявить проблемы предприятия и оперативно их решить. Кроме того, он не лишён ряда недостатков, которые существенно осложняют его использование. Часто эту проблему авторы ССП обходят в своих работах - многие из них, как уже говорилось, профессионально занимаются её распространением и не заинтересованы в освещении этого направления. Тем не менее информирование об этом аспекте необходимо для того, чтобы система могла совершенствоваться, а предприятия не сталкивались с некоторыми обидными проблемами, могли закрыть некоторые «бреши» системы. К чести отечественных авторов, они не увиливают от неприятной темы и подробно описывают те сложности, с которыми сталкиваются российские предприятия при внедрении системы сбалансированных показателей.

По мнению практикующих менеджеров, главным недостатком ССП является отсутствие (дефицит) средств оценки результата [5]. Отмечается сложность оценки ряда показателей. Во многом это связанно с тем, что такие факторы, как удовлетворённость работников, процент их обучения, доля постоянных клиентов и т.П., раньше вообще не принимались в расчёт предприятиями, соответственно, никак не измерялись. Однако решение этой проблемы - дело времени, так как с распространением системы методы сбора ин- 
формации будут совершенствоваться. Тесно связана с проблемой измерения ещё одна: в случае, если показатель не измеряем и может быть исключен, возможно нарушение цепи причинно-следственных связей, на которых построена вся сбалансированная система показателей. Тогда может понадобиться перестроение какой-то части системы, вплоть до изменения и перемещения некоторых целей, что ведёт к дополнительным затратам времени и средств.

Ещё одним недостатком менеджмент считает чрезмерное внимание к управлению через показатели, игнорирование системы «мягких» факторов [5]. То есть критикуется жёсткость системы по отношению к людям, игнорирование человеческого фактора. С другой стороны, прекрасно известно, что для эффективной работы экономической системы как раз важна максимальная отвлечённость от таких факторов. Минимализация человеческого аспекта часто служит мощным способом вывести предприятие на новый уровень эффективности и стабильности. Собственно, современная экономика строится на принципе рационализации, что и позволяет ей быть эффективной. Хотя, конечно же, в данном случае есть риск потери «человеческого лица» - «выжимание пота» приводит к тяжёлым психологическим и физическим последствиям среди рабочих. Соответственно, при дальнейшем совершенствовании системы в случае необходимости следует включить в неё некоторые «мягкие» показатели, способствующие гуманизации труда.

В исследовательском и «пропагандистском» плане затрудняет работу отсутствие какой-либо внятной, конкретной статистики, характеризующей эффективную работу ССП. Безусловно, есть в наличии данные о популярности использования системы (к примеру, использовании ССП 400 из 500 компаний Fortune-500 [6. C. 123]), каждая из книг наполнена множеством примеров успеха тех или иных предприятий. Но эти истории обычно содержат минимум конкретной количественной информации и имена многих компаний, по их желанию, заменены выдуманными. Соответственно, предприятиям, только готовящимся к внедрению системы, трудно судить о её эффективности - у них в наличии лишь косвенная информация. В этой связи ещё одним слабым местом в теории системы сбалансированных показателей является разный взгляд на необходимость конспирации при создании и использовании ССП. Создатели теории настаивают на непубличности её использования [1. С. 144] в связи с потенциальной полезностью для конкурентов. Однако возникает вопрос: если подробности системы, согласно правилам её внедрения, известны каждому работнику предприятия, как вообще можно сохранить её в тайне? Конкуренты при помощи самых простых и распространённых методов смогут добиться нужной информации от любого сотрудника предприятия. С другой стороны, не понятна полезность данной информации для конкурентов: каждая ССП разрабатывается под философию и особенности конкретного предприятия, которые им скорее всего известны. Соответственно, ценность получения конкурентами информации по ССП минимальна, а её слепое копирование вообще может отрицательно сказаться на состоянии предприятия-конкурента.

Классическое неприятие персоналом нововведений также часто имеет место при внедрении ССП: сбалансированная система показателей обяза- 
тельно проводится по инициативе «сверху», постепенно ретранслируясь «вниз» по управленческой схеме. По наблюдениям экспертов, это часто приводило к отсутствию мотивации и даже сопротивлению со стороны нижестоящего персонала. В данном случае вполне применимы классические и наиболее распространённые меры по ликвидации таких осложнений: от волевых решений руководителя до консенсуса, в зависимости от особенностей предприятия. Заметим, что некоторым образом увязывается с этой проблемой ещё один недостаток системы: отсутствие чётких механизмов разрешения управленческих конфликтов [5]. Хотя стоит заметить, что это не основной смысл создания системы. В неё можно включить цели и показатели, которые отражали бы стремление к снижению количества конфликтов, но прописывать механизмы решения этих проблем определённо не в её компетенции.

Стоит сказать ещё о нескольких проблемах, возникающих при внедрении системы, так как это довольно сложный процесс [7]:

- Размытость сроков внедрения (от нескольких недель до года, причём срок тяжело определить даже на первых этапах внедрения).

- Отсутствие быстрых результатов (первые результаты появляются спустя минимум полгода, максимальный срок составлял 3 года).

-Высокие затраты времени персонала. Для работы над ССП или хотя бы получения минимально необходимых знаний о ней следует пройти ряд курсов/тренингов практически каждому работнику компании. Топ-менеджмент вообще должен принимать в создании системы прямое участие, что сказывается на его повседневной деятельности.

- Кроме временных затрат, внедрение системы сбалансированных показателей очень затратно и в сугубо материальном плане. Только софт для системы обходится от 2000 долл. за одно рабочее место (не специализированная система, а только поддерживающая ССП) [8]. Учитывая тот факт, что стоимость софта составляет порядка $1 / 3$ от всей стоимости внедрения, несложно подсчитать примерные расходы на внедрение для каждого предприятия.

Целый ряд претензий к системе сбалансированных показателей предъявляется в сфере показателей. Сюда можно отнести уже упомянутые нами проблемы с недовольством только четырьмя составляющими и сложностью в определении показателей. Кроме того, многие предприятия столкнулись с проблемой излишне скрупулезного контроля: они вводили слишком много показателей либо акцентировались на незначительных моментах своей работы. Постоянно возникают сложности с переводом показателей на уровень подразделений, учитывая коренные различия многих из них [9. С. 32-33].

У достаточно большого количества компаний возникают сложности уже на этапе постановки целей [2. С.136]:

-Цель приравнивается к таким понятиям, как «проект», «стратегия», «миссия» и т.д.

-Большинство целей строится на прошлых представлениях о бизнесе.

- Цели не чёткие.

- Разбалансировка краткосрочных и долгосрочных целей.

- Не совпадают цели на разных уровнях организации. 
Заслуживающим внимание также является такой аспект критики, как многообразие предлагаемых вариаций ССП: у многих авторов свой взгляд на систему, требования к составляющим, показателям, схеме внедрения и т.д. Это размывает саму концепцию сбалансированной системы показателей и существенно осложняет менеджерам как процесс знакомства с ней, так и повседневную работу [10. С. 36].

Перечисленные выше сложности актуальны для всех регионов мира, однако известно, что на менеджмент очень сильно влияет национальная специфика. При внедрении ССП в нашей стране также возникли некоторые затруднения специфического характера. Связаны они, однако, в большей степени с отсталостью нашей страны в плане восприятия западных моделей управления. Ни для кого не является тайной, что на многих отечественных предприятиях такие слова, как «маркетинг», «стратегия» или «прогнозный бюджет», вызывают непонимание. Такие вещи до сих пор многим фирмам кажутся экзотикой и необязательным излишеством [10. С. 9]. В то же время наличие этих составляющих является обязательным условием внедрения ССП. Эти обстоятельства привели к выдающемуся явлению в мировой практике сбалансированной системы показателей: стратегию, системы бюджетирования, управленческого учёта и прочие элементарно необходимые вещи консалтинговым фирмам приходилось создавать параллельно с ССП, так как руководство предприятия зачастую даже не задумывалось об их необходимости [11. С. 88].

С относительной неэффективностью и невосприимчивостью российского менеджмента стоит связывать также следующие сложности при работе с ССП [12. С. 56-65]:

-Показатели сфокусированы не на стратегии, а на сторонних вещах.

- Недооценка важности составляющей персонала, а также процесса коммуникации с работниками в ходе внедрения и работы системы. Излишнее внимание к финансовой составляющей.

- Сложности с изменением психологии людей при переходе к системе заработка пропорциональны вкладу (что раньше было характерно только для рабочих профессий).

-Неоконченное внедрение. У менеджеров иногда не хватает терпения при внедрении системы, и они бросают процесс на середине пути. Иногда используется недоработанная система, что может нанести организации даже некоторый вред.

-Недооценка важности координации системы с мотивацией персонала, усугубляющаяся частой постановкой неверных либо нечётких целей и показателей.

Из всего вышесказанного можно сделать вывод о том, что, несмотря на достаточно большое количество недостатков и проблем ССП, они носят скорее временный или субъективный характер. Часть из них будет, видимо, разрешена со временем, в процессе совершенствования ССП. В то время как для избегания другой группы проблем требуется в первую очередь выверенная и чёткая работа менеджмента предприятия, чем будут нейтрализованы эти слабости. К тому же популярность данного метода подтверждает его высокое качество по сравнению с альтернативами, при всех его недостатках. Специ- 
фические российские проблемы, как мы выяснили, тоже скорее связаны с человеческим фактором, чем с недостатками ССП.

Обобщая всё сказанное, приходим к выводу, что, несмотря на значительные сложности, которые сопровождают внедрение сбалансированной системы в нашей стране, опыт внедрения данной технологии показывает высокий потенциальный эффект от её использования. Наиболее ценно в ней особое внимание к кадровой составляющей, обычно не слишком популярной составляющей системы управления. Возможность при помощи ССП сократить время и расходы на кадровую политику может стать решающим фактором для более активной работы менеджмента в области управления персоналом и, соответственно, большей производительности трудовой деятельности.

\section{Литература}

1. Каплан. Р., Нортон Д. Сбалансированная система показателей. От стратегии к действию. М.: ЗАО «Олимп-Бизнес», 2010. 320 с.

2. Браун М.Г. Система сбалансированных показателей на маршруте внедрения. М.: Альпина Бизнес Букс, 2005. 226 c.

3. Данилин O.A. Принципы разработки ключевых показателей эффективности (КПЭ) для промышленных предприятий и практика их применения // Управление компанией. 2003. № 2 (21). C. 11-15.

4. Трудовой кодекс Российской Федерации. М.: Проспект, 2010. 208 с.

5. Хорват П. Система сбалансированных показателей как средство управления предприятием [Электронный ресурс]: Консалтинговая компания «іТеат». Электрон. текст. данных. М.: ITeam, 2002-2013. Режим доступа: URL: http://www.iteam.ru/ articles.php?tid=2\&pid=1\&sid= $27 \& \mathrm{id}=221$ (дата обращения: 03.03.2014).

6. Фунщев В.В. Применение сбалансированной системы показателей в отдельно взятом дополнительном офисе банка // Менеджмент качества. 2010. № 2 (10). С. 122-132.

7. Разработка ССП. Методика [Электронный ресурс]. ГК «Современные технологии управления» Электрон. дан. URL: http://www.businessstudio.ru/procedures/ strategic/razrabotka bsc/ (дата обращения: 14.03. 2014).

8. Супонев П. Софт для системы сбалансированных показателей [Электронный ресурс]. CIMA. ru Электрон. текст. данных. Режим доступа: URL: http:// forum.cima.ru/ search.php? searchid=32194 (дата обращения: 15.03.2014).

9. Ольве Н.-Г., Рой Ж., Веттер М. Оценка эффективности деятельности компании: практ. руководство по использованию сбалансированной системы показателей. М.: Изд. дом «Вильямс», 2004. $304 \mathrm{c}$.

10. Хруцкий В.Е., Толмачёв Р.А. Оценка персонала. Критика теории и практики применения системы сбалансированных показателей. 2-е изд. М.: Финансы и статистика, 2007. 224 с. $224 \mathrm{c}$.

11. Кандалинцев В.Г. Сбалансированное управление предприятием. М.: Кнорус, 2006.

12. Гериун А.М., Нефедьева Ю.С. Разработка сбалансированной системы показателей: практ. руководство с примерами. М.: ЗАО «Олимп-Бизнес», 2005. 128 с.

\section{PROSPECTS FOR THE USE OF BALANCED SYSTEMS FOR PERSONNEL EVALUATION IN COMPANIES \\ I.V. Smirnov \\ Institute of Economics and Management, National Research Tomsk State University, Tomsk, Russia E-mail: Ilia.S91@yandex.ru}

Keywords: Balanced Scorecard; Enterprise assessment of staff; Management; Labor; Labor economics.

Since the mid-90s in the world of management the balanced scorecard gained popularity. It was developed by two American scientists, David Norton and Robert Kaplan. This system quickly gained popularity even among the world's largest corporations because of its simplicity and efficiency. This paper 
addresses the personnel component of the balanced system: its structure, features and value, as well as the possibility of its use for practical work of personnel departments of enterprises for a variety of industries. A special role is given to the consideration of the complexities involved in introducing a balanced system that is caused by its weak prevalence in the Russian practice. This article examines these issues and the issues related to overcoming them.

\section{References}

1. Kaplan R., Norton D. Sbalansirovannaya sistema pokazateley. Ot strategii $k$ deystviyu. Moscow, Olimp-Biznes Publ., 2010. 320 p.

2. Braun M.G. Sistema sbalansirovannykh pokazateley na marshrute vnedreniya. Moscow, Al'pina Biznes Buks, 2005. 226 p.

3. Danilin O.A. Printsipy razrabotki klyuchevykh pokazateley effektivnosti (KPE) dlya promyshlennykh predpriyatiy i praktika ikh primeneniya. Upravleniye kompaniyey, 2003, no. 2(21), pp. 11-15.

4. Trudovoy kodeks Rossiyskoy Federatsii. Moscow, Prospekt Publ., 2010. 208 p.

5. Khorvat P. Sistema sbalansirovannykh pokazateley kak sredstvo upravleniya predpriyatiyem. Available at: http://www.iteam.ru/ articles.php?tid=2\&pid=1\&sid= 27\&id=221 (accessed 03 March 2014).

6. Funtsev V.V. Primeneniye sbalansirovannoy sistemy pokazateley v otdel'no vzyatom dopolnitel'nom ofise banka. Menedzhment kachestva, 2010, no. 2(10), pp. 122-132.

7. Razrabotka SSP. Metodika. Available at: http://www.businessstudio.ru/procedures/ strategic/razrabotka_bsc/ (accessed 14 March 2014).

8. Suponev P. Soft dlya sistemy sbalansirovannykh pokazateley. Available at: http:// forum.cima.ru/ search.php? searchid=32194 (accessed 14 March 2014).

9. Ol've N.-G., Roy Zh., Vetter M. Otsenka effektivnosti deyatel'nosti kompanii: prakt. rukovodstvo po ispol'zovaniyu sbalansirovannoy sistemy pokazateley, Moscow, Vil'yams Publ., 2004. 304 p.

10. Khrutskiy V.E., Tolmachëv R.A. Otsenka personala. Kritika teorii i praktiki primeneniya sistemy sbalansirovannykh pokazateley, 2d edn. Moscow, Finansy i statistika Publ., 2007. 224 p.

11. Kandalintsev V.G. Sbalansirovannoye upravleniye predpriyatiyem. Moscow, Knorus Publ., 2006. 224 p.

12. Gershchn A.M., Nefed'yeva Yu.S. Razrabotka sbalansirovannoy sistemy pokazateley: prakt. rukovodstvo s primerami. Moscow, Olimp-Biznes Publ., 2005. 128 p.

Smirnov I.V. Perspektivy ispol'zovaniya sbalansirovannoy sistemy dlya otsenki kadrov predpriyatiy [Prospects for the use of balanced systems for personnel evaluation in companies]. Vestnik Tomskogo gosudarstvennogo universiteta. Ekonomika - Tomsk State University Journal of Economics, 2016, no. 4 (36), pp. 147-155. 